\title{
PELATIHAN MANAJEMEN PEMASARAN DIGITAL PADA WARGA BELAJAR PKBM INSAN KARYA
}

\author{
Feb Amni Hayati, Lia Asmalah, Nurmin Arianto, Putri Nilam Kencana, \\ Iis Noviyanti \\ Universitas Pamulang \\ Email: dosen01657@unpam.ac.id
}

\begin{abstract}
Insan Karya PKBM involves many components of society to become organizational strengths, as teachers and also volunteers. PKBM Insan Karya together with the community wants to realize free non-formal education that can embrace the lower middle class people who do not have access to formal education for various reasons or even children dropping out of school due to economic difficulties. The goals and objectives to be achieved in this Community Service (PKM) activity are to provide direction to the citizens learning PKBM Insan Karya in order to develop their abilities and participation in carrying out digital marketing management activities better. The method used in this Community Service (PKM) activity is to provide counseling and discussion in the context of socializing Providing direction to citizens learning PKBM Workers so that they can develop their capabilities and partitions in marketing management online with the zoom meeting application. With this counseling it is hoped that it can help citizens learn PKBM Insan Karya in order to be able to develop their abilities and participation in carrying out better marketing management activities.
\end{abstract}

Keywords: Counseling, Marketing, PKBM.

\begin{abstract}
Abstrak
PKBM Insan Karya melibatkan banyak komponen masyarakat untuk menjadi penguat organisasi, sebagai pengajar dan juga sukarelawan. PKBM Insan Karya bersama masyarakat ingin mewujudkan pendidikan nonformal gratis yang dapat merangkul masyarakat menengah ke bawah yang tidak mendapat akses pendidikan formal atas berbagai alasan atau pun anak putus sekolah karena kesempitan ekonomi. Adapun sasaran dan tujuan yang ingin dicapai dalam kegiatan Pengabdian Kepada Masyarakat (PKM) ini adalah Memberikan pengarahan kepada warga belajar PKBM Insan Karya agar dapat mengembangkan kemampuan dan partisipasinya dalam melakukan kegiatan manajemen pemasaran secara digital lebih baik. Metode yang digunakan dalam kegiatan Pengabdian Kepada Masyarakat (PKM) ini adalah memberikan penyuluhan serta diskusi dalam konteks mensosialisasikan Memberikan pengarahan kepada para warga belajar PKBM Insan karya agar dapat mengembangkan kemampuan dan partisiasinya dalam manajemen pemasaran melalui daring dengan aplikasi zoom meeting. Dengan adanya penyuluhan ini diharapkan agar dapat membantu warga belajar PKBM Insan
\end{abstract}


Karya agar dapat mengembangkan kemampuan dan partisipasinya dalam melakukan kegiatan manajemen pemasaran lebih baik.

Kata Kunci: Penyuluhan, Pemasaran, PKBM.

\section{A. PENDAHULUAN}

Tidak ada yang menyangkal bahwa pendidikan adalah hak dan kewajiban bagi setiap insan. Maka dengan itu tidak satupun orang diperkenan meninggalkan pendidikan, terlepas soal usia, keyakinan, ras, budaya, hak kepemilikan, dan juga stratanya. Dalam kontek Negara Indonesia, hal ini tercantum dalam UUD 1945 Pasal 31 Ayat 1-2 dan Pasal 28C. Walaupun demikian, di negara tercinta kita ini masih sangat banyak masyarakat yang tak mengenyam pendidikan, baik disebabkan oleh keterbatasan jangkauan kebijakan pemerintah maupun keenganan masyarakat itu sendiri untuk belajar atau bersekolah.

Tanggung jawab pembangunan pendidikan sebagaimana yang tertuang dalam UndangUndang Nomor 20 tahun 2003 tidak saja menjadi tanggung jawab pemerintah namun juga menjadi tugas dan tanggung jawab bersama antara masyarakat dan pemerintah. Akselerasi tujuan pendidikan pada prinsipnya harus dilaksanakan oleh lembaga pendidikan formal, nonformal dan informal yang menjadi bagian tak terpisahkan dalam mewujudkan tujuan pendidikan Nasional.

Fakta di masyarakat menunjukkan bahwa keberhasilan pendidikan di sekolahan formal belum mampu menjangkau pemerataan pendidikan kepada masyarakat. Itulah sebabnya pendidikan non formal menjadi faktor yang penting guna tercapainya pemerataan pendidikan. Diakui atau tidak saat ini jumlah siswa yang terancam putus sekolah terus meningkat, khususnya siswa pada jenjang pendidikan dasar Sembilan tahun. "Bank Dunia dalam laporannya mensinyalir bahwa dampak dari krisis ekonomi yang tidak kunjung usai, adalah anjloknya Angka Partisipasi Sekolah (APS), terutama anak-anak yang berasal dari keluarga miskin. Serta merosotnya kualitas sekolah, yang sebenarnya sebelum ke tahap kritis, tapi sudah sangat mengkhawatirkan.

Padahal keterlibatan masyarakat sudah diamanatkan dalam Undang-undang 20 tahun 2003 , tentang sistim pendidikan nasional yang menyatakan bahwa "Masyarakat berkewajiban memberikan dukungan sumber daya dalam penyelenggaraan pendidikan". Sehingga tanggung jawab pembangunan pendidikan tidak saja menjadi tanggung jawab pemerintah namun juga menjadi tugas dan tanggung jawab bersama antara masyarakat dan pemerintah. Akselerasi tujuan pendidikan pada prinsipnya harus dilaksanakan oleh lembaga Pendidikan Formal, nonformal dan informal yang menjadi bagian tak terpisahkan dalam mewujudkan tujuan pendidikan Nasional. Menurut Hasibuan (2012:1) Manajemen yaitu: "Ilmu dan seni mengatur proses pemanfaatan sumber daya manusia dan sumber-sumber lainnya secara efektif dan efisien untuk mencapai suatu tujuan tertentu".

Sedangkan menurut Manullang dalam bukunya Dasar-dasar Manajemen (2011:5) Manajemen yaitu: "seni ilmu perencanaan, pengorganisasian, dalam pengabdian kali ini, dimaksudkan untuk penyusunan, pengarahan dan pengawasan untuk mencapai tujuan yang sudah ditetapkan". Dalam pelaksanaannya, lembaga pendidikan non formal ini (termasuk PKBM Insan Karya) masih terseok-seok, karena masih ada kekurangan dari sana-sininya, terutama yang berkaitan dengan SDM-nya maupun dengan alat-alat yang mendukung. Bantuan pemerintah yang ada selama ini belum mampu menjadikan lembaga pendidikan non formal tersebut mengalami perkembangan (dalam arti signifikan), apalagi mandiri. Oleh 
karena itu kami melakukan pengabdian kepada masyarakat yang bertema "Pelatihan Manajemen Pemasaran Digital Pada Warga Belajar PKBM Insan Karya".

\section{B. METODE PELAKSANAAN KEGIATAN}

Metode yang digunakan dalam kegiatan Pengabdian Kepada Masyarakat (PKM) ini adalah memberikan penyuluhan serta diskusi dalam konteks mensosialisasikan Memberikan pengarahan kepada para warga belajar PKBM Insan karya agar dapat mengembangkan kemampuan dan partisiasinya dalam manajemen pemasaran melalui daring dengan aplikasi zoom meeting. Adapun tahapan-tahapan yang dilakukan dalam kegiatan ini yaitu:

Tahapan Persiapan

1. Mengirimkan proposal kegiatan Pengabdian Kepada Masyarakat (PKM). Kepada PKBM insan karya.

2. Konfirmasi kepada ketua PKBM Insan Karya untuk pelaksanaan kegiatan pelatihan dan penyuluhan.

3. Pembagian kerja (jobdesk) anggota kelompok PKM.

4. Penyusunan bahan/materi yang akan dibawakan saat kegiatan PKM berlangsung

\section{Tahapan Pelatihan}

1. Melakukan pemetaan terhadap kegiatan warga belajar PKBM Insan Karya mengenai apa saja yang telah dilakukan warga belajar PKBM Insan Karya.

2. Memberikan materi mengenai pentingnya peningkatan manajemen pemasaran digital pada warga belajar PKBM Insan Karya.

3. Memberikan materi peningkatan keahlian pemasaran digital pada warga belajar PKBM Insan Karya.

4. Mengadakan sesi diskusi untuk saling memberikan informasi mengenai kesulitan dan hambatan dalam pengembangan manajemen pemasaran secara digital

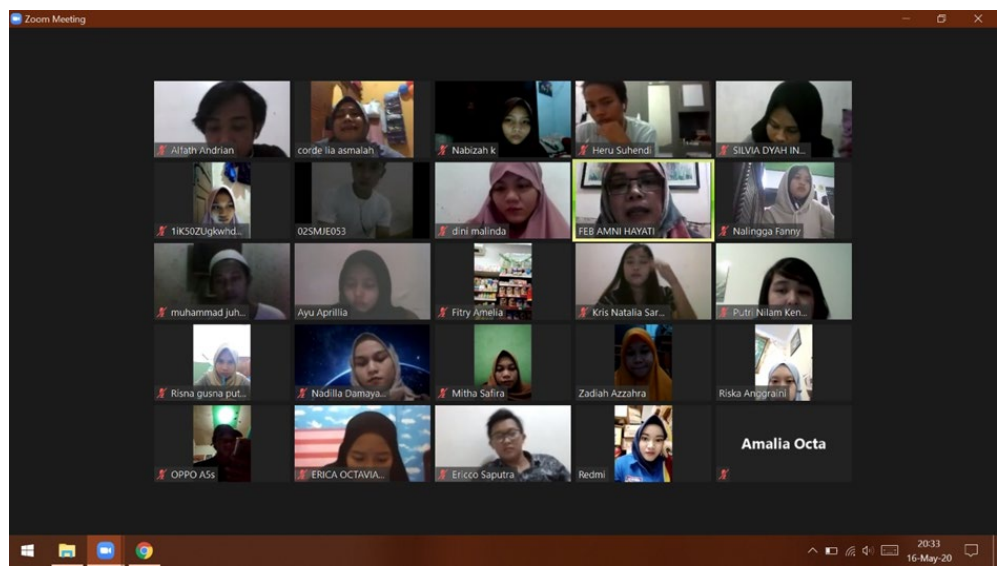

Gambar 1. Pasca Pemberian Materi 


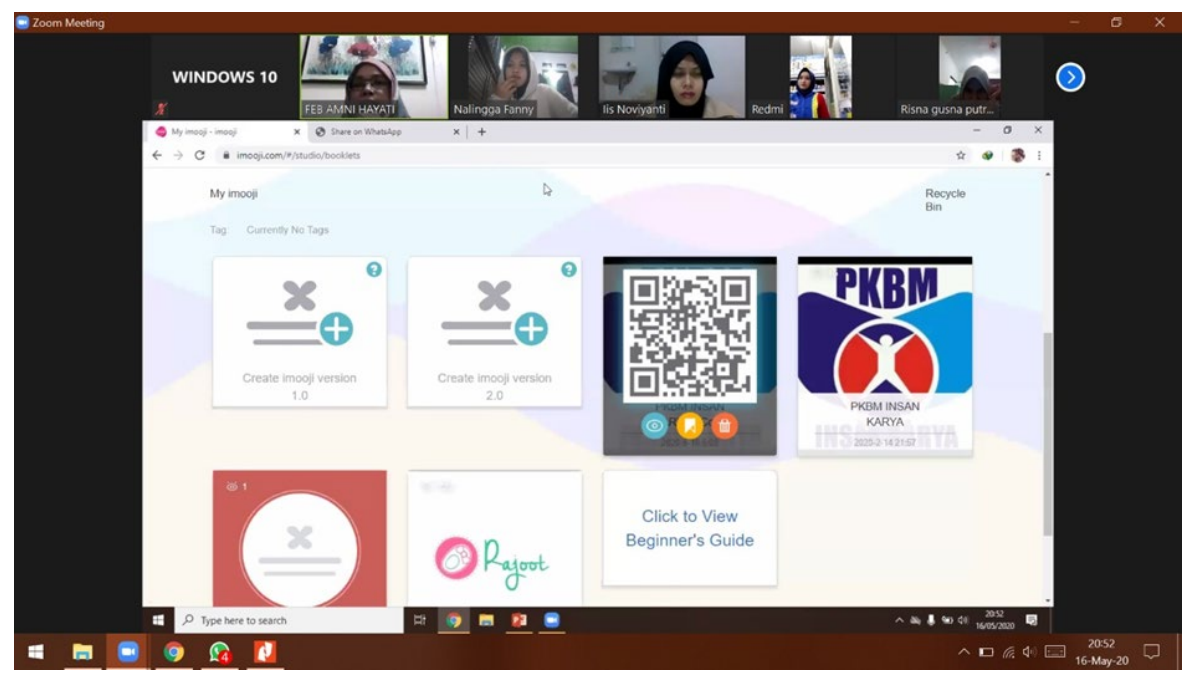

Gambar 2. Penjelasan Materi
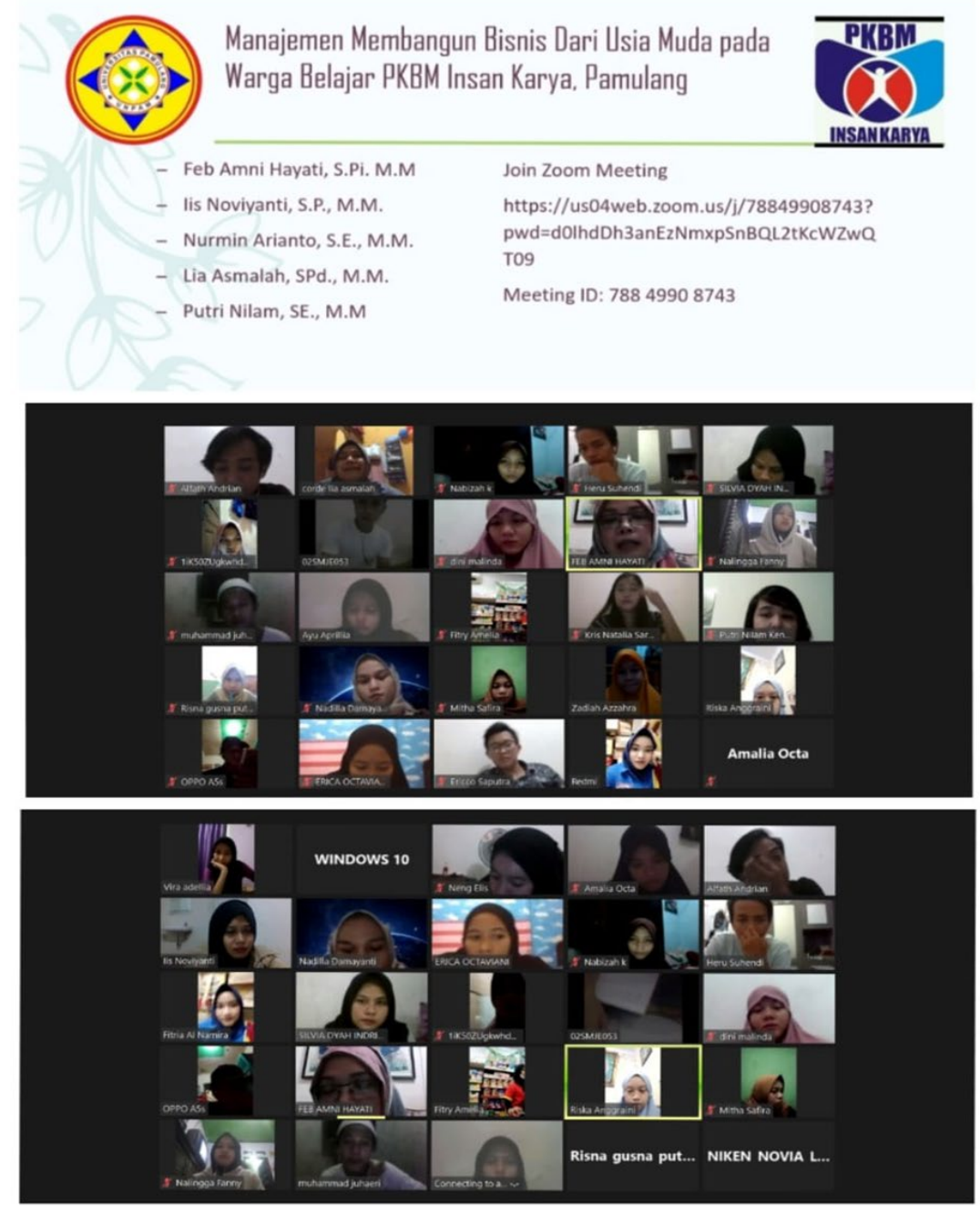

Gambar 3. Kegiatan Dengan Zoom Meeting 


\section{HASIL DAN PEMBAHASAN}

Dengan adanya penyuluhan ini diharapkan warga belajar PKBM Insan Karya agar lebih dapat mengembangkan kemampuan dan peran sertanya di dalam peningkatan kegiatan pemasaran secara digital. Melalui pelatihan ini warga belajar PKBM Insan Karya diharapkan belajar lebih banyak mengenai manajemen pengembangan pemasaran melalui aplikasi digital yang tentunya saat ini sangat diperlukan terutama dalam masa pandemic Covid 19 ini. Dimana pemasaran tidak dapat lagi dilakukan sebagaimana mestinya, karena berbagai macam keterbatasan, maka pemasaran melalui daring dapat menjadi solusi.

Dalam materi pertama oleh Feb Amni Hayati dengan judul materi Metode peningkatan manajemen pemasaran melalui aplikasi Emoji disampaikan bahwa dimasa sekarang ini dimana pemasaran tidak dapat lagi mengandalkan berita dari mulut ke mulut maka dibutuhkan media pemasaran yang lebih efektif untuk menjangkau segmen pasar, oleh karena itu diperlukan adanya kemampuan pada pelaku usaha atau calon pelaku usaha untuk memahami dan menggunakan aplikasi pemasaran online diantaranya adalah aplikasi emoji.com.

Dalam aplikasi ini pelaku usaha tidak hanya dapat memberikan informasi tentang produk dan tempat usaha saja tetapi mereka juga dapat memberikan informasi secara visual maupun audio yang mencakup keunggulan pruduk, harga, tempat, promosi dan pelanggan.

Materi kedua disampaikan oleh Putri Nilam Kencana, S.E.,M.M., dengan judul Materi Meningkatkan efektifitas pemasaran melalui Segmentasi pasar. Dalam materinya Putri Nilam Kencana, S.E.,M.M. diterangkan bahwa untuk dapat melakukan pemasaran yang lebih efektif maka pelaku usaha harus menentukan segmentasi pasar dari produk yang dibuat. Segmentasi pasar yang dimaksud meliputi segmentasi perilaku, segmentasi psychographis, segmentasi demografis, dan segmentasi geografis. Dengan penentuan segmentasi pasar yang jelas dan akurat maka pelaku bisnis dapat menentukan cara dan konten pemasaran yang disesuaikan dengan segmen pasar yang dituju.

Pelatihan ini diberikan kepada warga belajar PKBM insan Karya yang notabenenya adalah pelaku pelaku usaha non formal yang saat ini warga belajar yang telah memiliki usaha hanya menjalankan usahanya secara otodidak tanpa melakukan pemasaran maupun perencanaan pengembangan usaha. Dengan pelatihan ini diharapkan wara belajar PKBM Insan karya memiliki kemampuan untuk dapat memasarkan produk-produk yang mereka hasilkan dengan lebih baik melalui media digital dan juga memiliki kesadaran serta keinginan untuk dapat mengembangkan usahanya menjadi lebih baik dimasa yang akan datang.

\section{KESIMPULAN DAN SARAN}

\section{Simpulan}

Kegiatan Pengabdian Kepada Masyarakat (PKM) yang telah kami lakukan ini pada dasarnya adalah berkat kerjasama berbagai pihak terkait sehingga kegiatan dapat berjalan dengan baik dan terukur, serta materi yang kami sampaikan dapat warga belajar PKBM Insan Karya. Dengan adanya kegiatan Pengabdian Kepada Masyarakat (PKM) ini, diharapkan peserta dapat mengaplikasikan ilmu yang telah mereka peroleh dalam kehidupan sehari-hari. Dan pada akhirnya, ilmu tersebut dapat dirasakan manfaatnya oleh peserta sendiri dan lingkungan di sekitarnya, khususnya lingkungan warga belajar PKBM Insan Karya. 


\section{Saran}

Dari hasil pengabdian kepada masyarakat ini kami merekomendasikan kepada pemerintah dan dinas setempat agar:

1. Dengan adanya pelatihan ini kami melihat bahwa warga belajar sangat membutuhkan adanya pelatihan secara berkesinambungan yang tentang pengembangan usaha dan pemasaran melalui aplikasi digital.

2. PKBM sebagai tempat belajar diharapkan dapat memfasilitasi warga belajar untuk dapat memperoleh pelatihan pengembangan usaha dan pemasaran melalui aplikasi digital.

3. Pemerintah daerah diharapkan dapat membantu kegiatan pengembangan usaha kecil melalui kegiatan belajar di PKBM.

4. Institusi beserta akademisi diharapkan dapat berperan aktif untuk melakukan kegiatan pengabdian kepada masyarakat yang terkait dengan pengembangan usaha dan pemasaran.

\section{DAFTAR PUSTAKA}

Dumilah, R., Sunarto A., Ahyani, Solihin, D., Maulida H. (2020). Pelatihan Pemanfaatan Media Sosial Untuk Promosi Usaha Atau Bisnis Bagi Siswa. DEDIKASI PKM. Vol. 1. No. 1.

Fandy Tjiptono. (2000). Manajemen Jasa. Yogyakarta

Freddy Rangkuti, (2004), Riset Pemasaran. Cetakan Kelima. PT. Gramedia. Pustaka Utama. Jakarta.

Handoko, (2013). Manajemen; Edisi Kedua, Cetakan Ketiga belas, BPFE Yogyakarta.

Hasibuan, Malayu S.P. (2012). Manajemen Sumber Daya Manusia. Jakarta: PT.Bumi Aksara.

Hasibuan, Malayu, S.P. (2016). Manajemen Sumber Daya Manusia. Edisi Revisi. Jakarta: Penerbit PT Bumi Aksara.

Hasibuan, Malayu S.P. (2017). Manajemen Sumber Daya Manusia. Edisi Revisi. Jakarta: Bumi Aksara.

Herlambang, Susatyo. (2014). Basic Marketing (Dasar-dasar Marketing) Cara Mudah Memahami Ilmu Pemasaran.Yogyakarta : Gosyeng Publishing

M. Manullang, (2012). Dasar-dasar Manajemen Bagi Pimpinan Perusahaan. Jakarta. Gajah Mada Press.

Arikunto, Suharsimi. (2015) "Prosedur Penelitian Suatu Pendekatan Praktek", PT. Rineka Cipta, Jakarta.

Kotler, Philip (2006). Manajemen Pemasaran, Edisi Pertama. Indonesia: PT. Indeks Kelompok. Gramedia. 